\title{
ANSIEDAD GENERALIZADA Y AGRESIVIDAD INTRAESPECIFICA EN GATOS; DESCRIPCIÓN DE UN CASO CLÍNICO
}

\section{GENERAL ANXIETY AND INTRASPECIFIC AGGRESSION IN CATS: CASE REPORT}

Alabort Amundarain, S., Pineda González, S*., Olivares Moreno, A., Ibáñez Talegón, M.

Servicio de Etología Clínica. Departamento de Producción Animal. Universidad Complutense de Madrid, España. Correspondencia del autor *: stefaniapineda@ucm.es

\section{RESUMEN}

Acuden al Servicio Externo de Etología Clínica de la Universidad Complutense de Madrid referidos por su veterinario, dos gatos de raza común europea. Una hembra (Lily), castrada, con 2 años de edad, y un macho (Joe) castrado, con 8 años. El motivo de consulta por parte de los propietarios fue la agresividad de Joe hacia Lily. El especialista en medicina del comportamiento diagnosticó un trastorno de ansiedad generalizada, llegando a la conclusión de que dicha ansiedad producía la agresividad intraespecifica. El tratamiento consistió en un programa de modificación de conducta unido a la utilización de psicofármacos, y a un programa de enriquecimiento ambiental. También se utilizó el oligoelemento Magnesio. La terapia farmacológica empleada para Joe, fue Diazepam $(2 \mathrm{mg} / \mathrm{ml})$, unido a Fluoxetina $(20 \mathrm{mg} / 5 \mathrm{ml})$. En el caso de Lily se emplearon terapias complementarias, mediante la administración de 1 ampolla diaria del oligoelemento Magnesio. Tras 7 meses de tratamiento, la agresividad intraespecifica cesó.

Palabras clave: Agresividad, ansiedad, diazepam, fluoxetina, gato, magnesio, oligoelemento. 
Two european shorthair cats turned to The Ethology External Service of the Complutense University of Madrid, referred by their veterinarian. An 8 years old neutered male cat (Joe), and a 2 years old sterilized female cat (Lily). The purpose of the consultation reported by the owners, was the aggression from Joe to Lily. The specialist on animal behavior diagnosed a general anxiety disorder, concluding that the anxiety was leading to intraspecific aggression. The treatment consisted in a behavioral modification program linked to psychopharmacology therapy and environmental modification. It was also utilized the Magnesium trace element. The psychopharmacological treatment for Joe, consisted in the oral administration of Diazepam $(2 \mathrm{mg} / \mathrm{kg})$, and Fluoxetine $(20 \mathrm{mg} / 5 \mathrm{ml})$. Otherwise, Lily was treated with complementary therapies, using 1 ampoule of Magnesium trace element every 24 hours. After 7 months of therapy, the intraspecific aggression disappeared.

Keywords: aggression; anxiety; diazepam; fluoxetine; cat; magnesium; trace element.

\section{INTRODUCCIÓN}

Gran parte de los problemas del comportamiento en los gatos, se producen por un exceso de miedo y ansiedad. Estas dos emociones negativas tienen como objetivo protegerlos del daño que pueda causar un estímulo desconocido (Landsberg et al. 2016).

Tal como cita Chrousos (1992), diferentes factores pueden desencadenar elevados estados de estrés en el individuo, condicionando así su conducta no sólo con sus coespecíficos sino también con sus propietarios.

Cuando se produce un proceso estresante, se desarrolla una respuesta estereotipada, mediada por la activación del eje hipotálamo hipófisis-suprarrenal, donde también interviene el sistema nervioso autónomo. En la respuesta de estrés hay una gran cantidad de hormonas implicadas, como la $\mathrm{ACTH}$, los glucocorticoides, la prolactina y las catecolaminas (adrenalina y noradrenalina) (Matteri et al., 2000; McDermott et al., 2012). Muchos de los procesos estresantes, pueden desencadenar trastornos emocionales, tales como el miedo y/o la ansiedad (Gómez et al., 2002).

En principio, la ansiedad es adaptativa, proporcionada al estímulo que la origina y ha sido conservada a lo largo de la evolución (Gross, 1999). La diferencia entre la ansiedad normal y patológica, se encuentra principalmente en el grado de intensidad, frecuencia y duración de la 
respuesta (Spielberger et al., 1984).

La ansiedad generalizada se caracteriza por ser persistente y fluctuante en el tiempo, hace que el animal pase la mayor parte de tiempo en estado de alerta y tensión, afectando su bienestar emocional (Maier et al., 2000). Estudios realizados en diferentes especies han confirmado la relación existente entre la agresividad y la ansiedad (Parmigiani et al.,1999). Por otro lado, existen diversos factores que condicionan la aparición de conductas agresivas, como las respuestas endocrinas, los estados frustrantes, el aprendizaje del individuo y las características genéticas (Van den Berg et al., 2003).

La mayoría de las agresiones en los animales se producen cuando estos se encuentran con altos niveles de ansiedad (Parmigiani et al., 1999). La conducta agresiva, cursa con la activación de varios circuitos neuronales, donde participa el sistema límbico y diversos neurotransmisores neuroquímicos, como la serotonina o 5-hidroxitriptamina (5-HT) y las aminas (De Almeida et al., 2015). La 5-HT o serotonina es el principal neurotransmisor implicado en los procesos agresivos (Gowin et al., 2010). Varios estudios correlacionan los trastornos de ansiedad que cursan con agresividad, con bajos niveles de este neurotransmisor (De Boer y Koolhaas 2005). Por lo cual, la estrategia farmacológica empleada para aumentar los niveles de 5-HT consiste en usar precursores de 5-HT o inhibidores de la recaptación de 5-HT, (Caramaschi et al., 2007).

Por otro lado, diversos estudios muestran que alteraciones en el equilibrio homeostático de los oligoelementos, pueden provocar efectos negativos sobre la salud (Escanero et al., 2013). La oligoterapia intenta aportar al organismo aquellos oligoelementos que son necesarios para el óptimo funcionamiento celular, asegurando así el equilibrio del organismo. (Berthélémy, 2008).

Dentro de los oligolementos que ayudan a la función del sistema nervioso central destacan: Mg (Magnesio), Mn (Manganeso), Li (Litio), Se (Selenio) y Co (Cobalto),. En estados generales de fatiga psíquica y física, está indicado el empleo de $\mathrm{Mg}, \mathrm{Mn}, \mathrm{Li} \mathrm{y} \mathrm{Se}$. Por otro lado, en trastornos como estados depresivos, ansiedad, nerviosismo, insomnio y fatiga psíquica, los oligoelementos tales como el $\mathrm{Mg}, \mathrm{Mn}, \mathrm{Li}$ y $\mathrm{Co}$, ejercen un efecto benefícioso (Torti, 2000).

\section{DESARROLLO DEL CASO CLÍNICO}




\section{HISTORIA CLÍNICA}

Joe es un gato macho común europeo de 8 años de edad, castrado, de 4,9 $\mathrm{kg}$ de peso y adoptado a los 3 meses. Sus propietarios decidieron adoptarlo por medio de unos conocidos, con el objetivo de tener un animal de compañía. Lily es una hembra común europea, castrada, de 2 años.

Los dos gatos viven en un piso de $90 \mathrm{~m} 2$, donde permanecen el $100 \%$ del tiempo encerrados en casa. El entorno familiar está formado por 4 miembros (la madre, el padre, la hija y el hijo). Los gatos tienen acceso a toda la vivienda y duermen en cualquier habitación de la casa. $\mathrm{Su}$ alimentación consiste en un $90 \%$ de alimento seco y el 10\% del alimento es enlatado. Reciben la comida en la cocina, ad libitum.

Joe es un animal tranquilo, que rechaza las caricias en exceso. La presencia de la hembra lo estresa la mayor parte del tiempo. No reacciona frente a desconocidos. Su nivel de actividad general y excitabilidad es moderado, y su nivel de obediencia es bueno. Presenta una conducta social buena con los miembros de la familia, y en situaciones de aislamiento y/o separación no tiene problemas, y no presenta maullidos excesivos.

Las bandejas de deposiciones se encuentran en la terraza y en la cocina, no están cubiertas y tienen un tamaño de $40 \times 10 \mathrm{~cm}$. La arena es sin olor, y los gatos no han respondido con cambios de conducta a la modificación de la arena o la bandeja. La arena se cambia cada 3 semanas. Las bandejas las usan los 2 gatos indistintamente, y actúan de forma indiferente ante la presencia de animales o personas durante la eliminación.

A la consulta del Servicio de Etología Clínica los propietarios vienen remitidos por su veterinario de cabecera, debido a que Joe muestra conductas agresivas hacia Lily. Los problemas comenzaron cuando la gata llegó a la etapa adulta. Los dueños intentaron corregir el problema separando a los animales, e implementando los gritos como castigo. Joe respondía a esos enfrentamientos incrementando su agresividad, por lo cual se presentaban episodios de agresividad redirigida hacia sus dueños.

El primer episodio se dio en el primer celo de la gata, antes de su esterilización. El macho atacó a la familia. El problema se solucionó temporalmente con la esterilización de la hembra. Sin embargo, meses después volvieron a ocurrir los enfrentamientos. La situación empeoró, debido a que la hembra provocaba a Joe con bufidos aumentando aún más los episodios de agresividad en el grupo social. 


\section{DIAGNÓSTICO Y PRONÓSTICO}

Una vez realizado el examen físico-clínico y la evaluación del comportamiento, por parte de los veterinarios especialistas en medicina del comportamiento, se diagnosticó una agresividad intraespecífica cuya causa inmediata fue un trastorno de ansiedad generalizada. El pronóstico dado por el terapeuta fue reservado, pues debemos tener presente que el éxito de la terapia depende de diferentes factores externos, como la cooperación de los propietarios (Mills, 2006). Igualmente el pronóstico se realizó teniendo en cuenta la intensidad del desorden del comportamiento, y la actitud del propietario ante el problema.

\section{TRATAMIENTO}

Una vez analizado el caso, el tratamiento se enfocó en reducir la ansiedad presente en el grupo social, y reducir los niveles de estrés del macho, con el objetivo de mejorar la relación social entre los animales, y restablecer el equilibrio familiar. Para ello, se implementaron técnicas de modificación de conducta, planes de enriquecimiento ambiental, terapia farmacológica y terapias complementarias.

\section{$\underline{\text { Terapia de modificación de conducta }}$}

Con el fin de evitar episodios que produzcan ansiedad en el gato, se realizó una separación física de los dos animales durante dos semanas. La mitad de la casa estaba disponible para uno de los animales y la otra mitad, para el otro, cada uno con su plato de comida y sus objetos de valor (juguetes, cama, bebedero, etc.). Durante este período, no debía haber ningún contacto visual, por lo que se separaron mediante una puerta. Transcurridas las dos semanas, se permitió el contacto visual, separándolos por una malla.

Se indicó a los propietarios que debían premiar a los animales cuando interactuaran de forma relajada y amigable tras la malla. Los premios consistían en comida o juguetes que produjeran una gran motivación para los gatos, pero sólo se podían emplear en esta determinada situación. No debían poner este premio a su disposición en el juego normal o junto con el pienso.

Para mejorar la relación de los gatos con los propietarios, se estableció un protocolo que consistía en ignorar las conductas no deseadas de los animales y premiar las conductas correctas. La iniciativa debía partir siempre de los propietarios, por lo que en situaciones donde los animales pidieran algo o tuvieran la iniciativa, se debía ignorar la petición.

\section{Enriquecimiento ambiental}


Para disminuir los niveles de ansiedad del gato y mejorar el entorno y el nivel de bienestar de los dos animales, se establecieron unas pautas de enriquecimiento ambiental. Se realizaron cambios en la rutina de alimentación, de juego, y en la relación social con los humanos.

Respecto a la alimentación, se aumentaron los niveles de comida húmeda en Joe, y en Lily se enriqueció la cena con pavo. También se les indico a los dueños la necesidad de comprar o construir juguetes interactivos y de búsqueda para gatos, dicho juego se debía realizar con cada gato por separado, en una frecuencia de 5-10 minutos al día, 3 veces al día. Por otro lado, debían tener a su disposición distintos juguetes cognitivos mientras no estuvieran con los propietarios. El objetivo de los juegos consiste en modificar el ambiente para mantener a los animales ocupados, y entretenidos para aumentar el gasto de energía, disminuyendo así los niveles de ansiedad (Ibáñez y Anzola, 2009).

Otra parte del enriquecimiento consistió en emplear música relajante, al igual que aromas tranquilizantes, como, por ejemplo, esencia de lavanda, espliego y camomila. El objetivo de este cambio en el ambiente es mantener un ambiente relajado y por consiguiente, disminuir los niveles de ansiedad, evitando así que se desencadene el conflicto entre los animales.

\section{Terapia farmacológica}

Se implementó una terapia farmacológica para favorecer los resultados de la terapia de modificación de conducta y disminuir el nivel de ansiedad que sufría Joe, ya que debemos tener presente que tal como citan diferentes autores como Loo et al., (1990), y Overall, (1999), el tratamiento farmacológico puede favorecer la implementación del plan de modificación de conducta, facilitando el aprendizaje, ya que permite la disminución de los niveles de ansiedad. Por otro lado, la terapia farmacológica no sólo permite la respuesta positiva del animal, sino que también permite lograr la motivación suficiente de los propietarios para llevar a cabo el plan de modificación de conducta y el enriquecimiento ambiental.

En este caso se administró Fluoxetina solución de $20 \mathrm{mg} / \mathrm{kg}$ vía oral, con una dosis de 0,5ml cada 24 horas, debiéndose administrar con una jeringa insulínica, para facilitar la dosificación. También se administró Diazepam en gotas de $2 \mathrm{mg} / \mathrm{ml}$, vía oral, a dosis de $0,2 \mathrm{ml}$ cada 8 horas.

\section{Terapias complementarias}

Con el fin de favorecer la terapia de modificación de conducta, se instauró una terapia 
complementaria a Lily, la cual consistía en la administración de oligoelementos. El oligoelemento de elección fue el Magnesio, pues tal como cita Torti (2000), su uso es adecuado para trastornos como estados depresivos, ansiedad, nerviosismo, insomnio y fatiga psíquica. Se administró 1 ampolla de magnesio cada 24 horas.

\section{ANÁLISIS Y EVOLUCIÓN DEL CASO}

En el caso de los problemas del comportamiento es fundamental realizar una evolución del caso, y establecer nuevas pautas a realizar durante el proceso. La comunicación con los clientes es imprescindible para resolver problemas y apoyarle durante la terapia. En los seguimientos los propietarios deben indicar los avances o los problemas que tienen durante todo el proceso de terapia, y el veterinario especialista debe estudiar la evolución del caso con el fin de realizar modificaciones en la terapia propuesta (Askew, 2005).

A partir de la primera consulta, se realizó el seguimiento de Joe y Lily periódicamente y según la evolución mostrada.

El primer seguimiento se realizó a los 14 días, los propietarios indicaron que separaron a los animales y que en unos días pondrían la malla recomendada.

Transcurridos 8 días después del primer seguimiento, comentaron que ya habían puesto la malla, y que la gata no mostraba signos de agresividad hacia el macho y además los dos gatos intentaban jugar tras la malla. En este momento se indicó como realizar la retirada paulatina del Diazepam.

Tras 1 mes y medio, se realizó otro seguimiento telefónico. Los propietarios indicaron que los gatos estaban más relajados, aunque observaron un episodio de agresividad redirigida en presencia de extraños. Se explicó cómo no reforzar la conducta y se enfatizó en la necesidad de evitar el conflicto, no exponiendo a los gatos a personas extrañas. Se empezó a retirar la malla con terapia de desensibilización sistemática, por períodos de 5 minutos sin los dueños estar presentes. Siempre que los gatos interactuaban con tranquilidad, debían ser premiados.

A los 15 días, después de haber retirado la malla los propietarios vuelven a llamar. Juntaron a los dos animales tal como lo había recomendado el especialista, pero a los 3 días fue esta vez la hembra quien atacó al macho. Explicaron que el gato estaba más tranquilo y menos reactivo. Sin embargo, comentan que la gata durante la época de separación residía en la cocina, junto al frigorífico y que los ataques se daban cerca de la zona, produciéndose respuestas agresivas 
como protección a los recursos de esta área. Se recomienda volver a poner la malla, pero cambiando a la gata al otro lado de los recursos alimenticios. A las dos semanas se debería retirar nuevamente la malla y juntar a los animales por períodos cortos de tiempo (5 minutos), premiando las conductas de relajación.

Transcurrido 1 mes, de haberlos juntado nuevamente, los propietarios explicaron que nada había mejorado con el cambio de lugar. La hembra estaba más ansiosa y se excitaba al darle el pavo, gruñendo a los propietarios. Por lo tanto, se recomienda no dar pavo a la gata cerca del lugar donde ocurren los encuentros, ni en presencia del macho.

Nueve días después, se volvió a hacer un seguimiento telefónico. Los gatos ya no se peleaban. Los niveles de ansiedad habían bajado, permitiendo el aprendizaje de las normas de convivencia. Se observaron mejorías en la interacción entre los dos gatos. También desapareció la protección a recursos por parte de Lily, y se indica que en un mes se retiraría la Fluoxetina a Joe y que el Magnesio de Lily se retirará con la finalización de los comprimidos que tenían en el domicilio.

Finalmente transcurrido 1 mes, los propietarios indicaron que la situación había mejorado favorablemente. Se realizó la retirada paulatina de la fluoxetina.

\section{CONCLUSIONES}

La terapia combinada con psicofármacos (Fluoxetina + Diazepam), el enriquecimiento ambiental y el plan de modificación de conducta implementado, permitió controlar los niveles de ansiedad en Joe, permitiendo así el aprendizaje y la comprensión de la situación, y dando lugar a una correcta interacción social. Igualmente, el oligoelemento Magnesio, junto con la terapia de comportamiento, permitió disminuir la excitabilidad en Lily, aumentando su estado de relajación, lo que finalmente disminuyó la ansiedad y de esta forma desaparecieron los conflictos entre los dos animales.

\section{BIBLIOGRAFÍA}

Askew HR. Tratamiento de los problemas de comportamiento en perros y gatos: guía para el 
veterinario de pequeños animales. : Inter-Médica; 2005.

Berthélémy, S.Oligoéléments, des microéléments pour l'oligothérapie: Actualités Pharmaceutiques; 2008; 47 (472)

Caramaschi D, de Boer SF, Koolhaas JM. Differential role of the 5-HT 1A receptor in aggressive and non-aggressive mice: An across-strain comparison. Physiol Behav 2007;90(4):590-601.

Chrousos GP, Gold PW. The concepts of stress and stress system disorders: overview of physical and behavioral homeostasis. JAMA 1992;267(9):1244-1252.

De Almeida, Rosa Maria Martins, Cabral JCC, Narvaes R. Behavioural, hormonal and neurobiological mechanisms of aggressive behaviour in human and nonhuman primates. Physiol Behav 2015;143:121-135.

De Boer SF, Koolhaas JM. 5-HT 1A and 5-HT 1B receptor agonists and aggression: a pharmacological challenge of the serotonin deficiency hypothesis. Eur J Pharmacol 2005;526(1):125-139.

Escanero J, Soria M, Guerra M. Contribución actual de los elementos traza y minerales en medicina. Su papel clínico.Textos docentes: Universidad de Zaragoza 2013.

Gómez C, Saldívar-González JA, Rodríguez R. Modelos animales para el estudio de la ansiedad: una aproximación crítica. Salud Mental 2002;25(1):14-24.

Gowin JL, Swann AC, Moeller FG, Lane SD. Zolmitriptan and human aggression: interaction with alcohol. Psychopharmacology (Berl ) 2010;210(4):521-531.

Gross JJ. Emotion regulation: Past, present, future. Cognition \& Emotion 1999;13(5):551-573.

Horwitz DF, Mills DS, Heath S, Wols MB. Manual de comportamiento en pequeños animales. : Ediciones S Madrid; 2006.

Johnson EO, Kamilaris TC, Chrousos GP, Gold PW. Mechanisms of stress: a dynamic overview of hormonal and behavioral homeostasis. Neuroscience \& Biobehavioral Reviews 1992;16(2):115-130.

Landsberg G, Milgram B, Mougeot I, Kelly S, de Rivera C. Therapeutic effects of an alpha-casozepine and L-tryptophan supplemented diet on fear and anxiety in the cat. Journal of Feline Medicine and Surgery 2016:1098612X16669399.

Loo H, Zarifian E, Boulenger JP, Davy JP. Psychotropic drugs. The drugs to prescribe. Rev Prat 1990 Apr 11;40(11):1043-1064.

Maier W, Gänsicke M, Freyberger H, Linz M, Heun R, Lecrubier Y. Generalized anxiety disorder (ICD-10) in primary care from a cross-cultural perspective: a valid diagnostic 
entity? Acta Psychiatr Scand 2000;101(1):29-36.

Matteri R, Carroll J, Dyer C. Neuroendocrine responses to stress. The biology of animal stress.CABI Publishing 2000:43-76.

McDermott CM, Liu D, Schrader LA. Role of gonadal hormones in anxiety and fear memory formation and inhibition in male mice. Physiol Behav 2012;105(5):1168-1174.

Overall KL. Clinical behavioral medicine for small animals. : Mosby-Year Book, Inc.; 1997.

Parmigiani S, Palanza P, Rodgers J, Ferrari PF. Selection, evolution of behavior and animal models in behavioral neuroscience. Neuroscience \& Biobehavioral Reviews 1999;23(7):957-970.

Torti A. Principios de Oligoterapia: Los oligoelementos como catalizadores y la medicina funcional. Natura Medicatrix: Revista médica para el estudio y difusión de las medicinas alternativas 2000(58):18-25.

Van den Berg L, Schilder M, Knol B. Behavior genetics of canine aggression: behavioral phenotyping of golden retrievers by means of an aggression test. Behav Genet 2003;33(5):469-483. 